\title{
ANALISIS KEGAGALAN PIPA BOILER SUPERHEATER PADA PABRIK KELAPA SAWIT
}

\author{
Lusiana $^{1}$, Fatayalkadri Citrawati ${ }^{1}$, Erie Martides ${ }^{2}$, Gugum Gumilar ${ }^{3}$ \\ ${ }^{1}$,Pusat Penelitian Metalurgi dan Material, LIPI \\ Kawasan PUSPIPTEK, Gedung 470, Serpong, Indonesia \\ ${ }^{2}$.Pusat Penelitian Tenaga Listrik dan Mekatronik, LIPI \\ ${ }^{3}$ Balai Besar Logam dan Mesin, Kementerian Perindustrian \\ lusianand@yahoo.com
}

\begin{abstract}
ABSTRAK
Terjadi kegagalan pada pipa boiler superheater dengan material ASTM A213 T12 di sistem pembangkit yang berada di Pabrik kelapa sawit setelah pemakaian selama 4,5 tahun. Pipa boiler yang bekerja pada temperatur $600^{\circ} \mathrm{Cdan}$ tekanan 80 bar mengalami kerusakan berupa pecah pada bagian tengah dengan indikasi adanya bulging pada bagian tengah sejajar sumbu axis disertai penipisan ketebalan pipa dan hadirnya produk korosi. Investigasi dengan metode analisa kegagalan dilakukan melalui beberapa pemeriksaan dan pengujian merusak untuk mengetahui penyebab kegagalan, yaitu pengamatan visual, pemeriksaan komposisi kimia menggunakan spectroskopi, pengujian kekerasan menggunakan micro vickers tester, dan pengamatan struktur mikro menggunakan optical microsccopy dan scanning electron microscopy (SEM). Adanya unsur krom pada bagian yang mengalami pecah yang jumlahnya di bawah range sangat mempengaruhi penurunan terhadap ketahanan korosi dan nilai kekerasan. Batas butir dari fasa ferit pada struktur mikro menipis dengan ukuran butir yang membesar sebagai akibat telah mengalami sperodisasi dan dekarburisasi serta korosi sumuran dari pemeriksaan SEM pada kerak produk korosi. Hasil analisis menyatakan bahwa pipa boiler superheater mengalami pecah dari dalam dengan inisiasi penipisan ketebalan sebagai akibat dari korosi sumuran pada dinding dalam pipa, yang menyebabkan pipa boiler superheater mengalami pemanasan berlebih pada kondisi operasi temperatur dan tekanan tinggi, sehingga pipa menerima beban panas berlebih dan terjadi pecah.
\end{abstract}

Kata kunci: pipa boiler superheater, pecah,analisis kegagalan, pemanasan berlebih, korosi sumuran

\begin{abstract}
Failure Analysis Of Superheater Boiler Pipe In Palm Oil Factory. There was a failure in the superheater boiler pipe with ASTM A213 T12 material after 4.5 years of use. Boiler pipes that work at a temperature of $600{ }^{\circ} \mathrm{C}$ and a pressure of 80 bar suffer damage in the form of a rupture in the middle with an indication of bulging in the middle parallel to the axis along with thickness of wall thickness pipe and the presence of corrosion products. Investigation with the failure analysis method is carried out through several dectructive test to find out the cause of the failure, namely visual observation, chemical composition examination using spectroscopy, hardness testing using micro vickers tester, and micro structure observation using optical microscopy and scanning electron microscopy (SEM). The presence of chrome elements in the superheaterboiler pipe that is broken which amount is below the range greatly affects the decrease in corrosion resistance and hardness value. The grain boundary of the ferrite phase in the microstructure is thinned with an enlarged grain size as a result of phenomenon of sperodization and decarburization and pitting corrosion from the SEM examination on the corrosion product. The results of the analysis stated that the superheater boiler pipe broke from the inside with the initiation of thinning of wall thickness pipe as a result of pitting corrosion in the inner wall of the pipe, which causes the superheater boiler pipe occurs overheat in high temperature and pressure operating conditions, so that the pipe received excessive heat load and broke .
\end{abstract}

Keywords: superheater boiler pipe, rupture, failure analysis, overheating, pitting corrosion 


\section{PENDAHULUAN}

Boiler merupakan komponen vital dalam sistem pembangkit yang di disain befungsi menghasilkan uap panas sampai dengan tekanan tertentu untuk kemudian mengalirkan panasnya ke suatu proses. Pemilihan material, perlakuan serta proses perawatan untuk aplikasi boiler yang dikenai beban kerja tekanan pada temperatur yang tinggi sangat diperhatikan, karena sangat rentan terhadap kegagalan korosi, keausan, mulur yang berakibat menurunkan umur pakai komponen dari yang direncanakan [1]. Material ASTM A213 adalah baja karbon feritik dan austenitik yang seringkali digunakan untuk aplikasi komponen superheater dan pipa heat exchanger,karena memiliki kandungan unsur krom yang akan meningkatkan ketahanan terhadap korosi dan oksidasi temperatur tinggi, serta meningkatkan ketahanan keausan dan abrasi. Unsur lain yang sengaja ditambahkan pada ASTM A213 adalah Molibdenum yang berfungsi meningkatkan ketahanan dan kekuatan pada temperatur tinggi, sepertu ketahanan terhadap creep dan mencegah terjadinya temper embrittlement [2][3].

Pada proses pengolahan kela7pa sawit di didaerah Kalimantan Selatan, melibatkan pembangkit untuk menghasilkan Crude Palm Oil (CPO). Uap panas yang terbentuk pada boiler superheater hasil pembakaran bahan bakar di sistem pembangkit didistibusikan ke unit pengolahan pada pabrik [4].. Proses produksi menghasilkan CPO harus dilakukan sesuai dengan prosedur kerja dengan tetap memperhatikan jadwal perawatan berkala agar tidak terjadi kegagalan pada sistem yang akan menghambat produktivitas dan berujung pada kerugian akibat terhentinya proses produksi.

Pembangkit pada pengolahan kelapa sawit menggunakan bahar bakar berupa campuran antara batubara dengan ampas inti kelapa sawit yang dikenal dengan Palm Kernel Meal (PKM). campuran bahan bakar tersebut. Pada Desember 2018 telah terjadi kegagalan pada pipa boiler superheater di sistem pengolahan kelapa sawit (boiler power plant 2A), yang berlokasi di Batu Licin, Kalimantan Selatan. Kegagalan yang terjadi yaitu berupa pengembungan pipa dan pecah pada bagian tengah dinding pipa boiler yang umur pakainya telah digunakan selama 4,5 tahun. Untuk mengetahui penyebab dari kegagalan pipa boiler superheater dilakukan investigasi dengan teknik analisis kegagalan melalui beberapa pemeriksaan dan pengujian merusak pada komponen. Hasil analisis digunakan sebagai acuan agar kejadian yang serupa tidak terulang lagi di masa mendatang.

\section{METODOLOGI}

Pada penelitian untuk mengetahui penyebab dari kegagalan pipa boiler superheater pada pabrik pengolahan kelapa sawit dilakukan dengan metode analisis kegagalan yang meliputi: teknik wawancara di tempat terjadinya kegagalan yaitu di Kalimantan Selatan, pemeriksaan visual dan pengambilan data operasi, kemudian dilanjutkan dengan pengujian merusak di laboratorium diantaranya yaitu pengujian kekerasan, pemeriksaan komposisi kimia dan pengamatan struktur mikro. Data spesifikasi dan data operasi pipa boiler superheater di pabrik pengolahan kelapa sawit dapat dilihat pada tabel 1.

\section{A. Pengamatan dan studi literatur}

Ketika terjadi kegagalan pada pipa boiler superheater, dilakukan pengamatan dan pengambilan spesimen dan bukti yang mengarah pada penyebab terjadi kegagalan. Pengambilan data di lapangan melalui teknik wawancara terhadap operator, pengamatan visual makroskopis, dan pengambilan data operasi serta spesifikasi dari sistem pembangkit pada pabrik pengolahan kelapa sawit.

\section{B. Preparasi spesimen}

Setelah pengambilan sampel pipa boiler superheater yang mengalami kegagalan, kemudian dilakukan proses persiapan spesimen yang sesuai standar untuk dilakukan proses pengujian laboratorium. Preparasi spesimen meliputi pemotongan, mounting, grinding dan polishing.

Tabel 1.Data spesfikasi dan operasi pipa boiler

\begin{tabular}{ll}
\hline Temperatur kerja boiler & 80 barr \\
Temperatur steam & $600^{\circ} \mathrm{C}$ \\
Komposisi bahan bakar & batubara 70\% dan \\
& palm kernel milk \\
& $30 \%$ \\
\hline
\end{tabular}



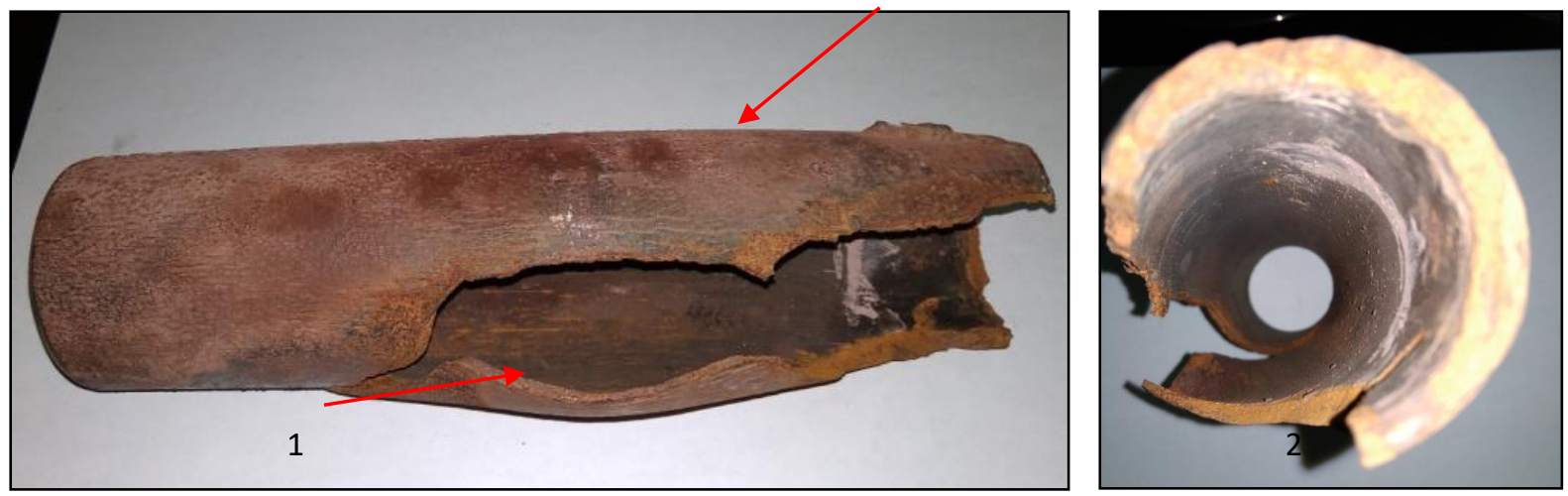

Gambar 1. Pemeriksaan visual dan posisi pengujian pipa boiler superheater

\section{Pemeriksaan komposisi kimia}

Metode spectroscopy menggunakan spektrometer digunakan untuk memeriksa komposisi unsur-unsur kimia pada material pipa boiler superheater, yang kemudian hasilnya dibandingkan dengan spesifikasi standar material pipa boiler baru atau yang tidak mengalami kegagalan.

\section{Pengujian kekerasan}

Pengujian kekerasan pada analisis kegagalan ini menggunakan metode micro vickers dengan identor intan yang mengacu pada standar ASTM E92 [5] dengan tujuan untuk mengetahui perbedaan kekerasan pada material yang mengalami kegagalan dan material pipa boiler baru. Pengujian dilakukan pada 3 titik pengujian dari yang dekat dengan bagian pecah hingga yang terjauh.

\section{E. Pengamatan struktur mikro}

Pengamatan secara mikroskopik dengan metode metalografi dilakukan untuk menganalisa morfologi dan distribusi butir serta fasa yang terbentuk pada material pipa boiler superheater yang mengalami kegagalan yang mengacu pada standar ASM Handbook Volume 9(2004) [6]. Pengamatan struktur mikro pada material pipa boiler superheater menggunakan metode scanning electron microscopy (SEM) Jeol JSM 6390 A dengan teknik back scattered electron dan mapping.

\section{HASIL DAN PEMBAHASAN}

Pengamatan visual pada pipa boiler superheater yang terjadi kegagalan dapat dilihat pada gambar 1, dimana dari gambar tersebut pipa di indikasikan adanya bulging atau mengelembung pada bagian tengah yang sejajar dengan dengan sumbu axis atau pada arah longitudinal yang disertai penipisan ketebalan. Dari hasil pengamatan visual tersebut juga terlihat adanya produk korosi diseluruh bagian pipa, yaitu berwarna kuning kecoklatan dan kasar. Adanya produk korosi tersebut sebagai indikasi yang menyatakan adanya reaksi dari gas bakar dan pipa bagian luar terekspos pada temperatur di atas

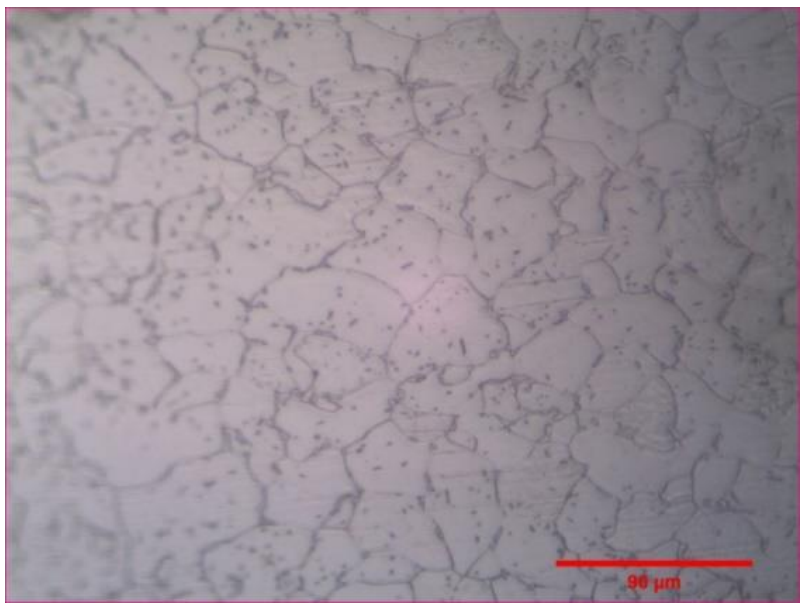

(a)

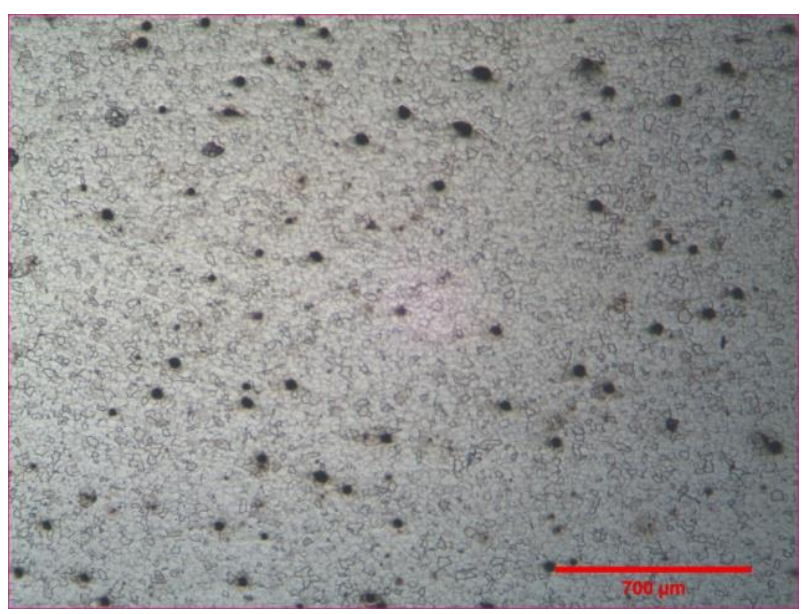

(b)

Gambar 2.(a),(b) Struktur mikro pipa boiler posisi 1 
normalnya yang seharusnya diterima oleh material pipa boiler superheater.

Tabel 2 merupakan tabel pemeriksaan komposisi kimia pada pipa boiler superheater yang mengalami kegagalan yang kemudian dibandingkan dengan komposisi kimia pada material awal pipa boiler yaitu ASTM A213 grade T12. Dari hasil pemeriksaan komposisi kima, dengan posisi pemeriksaan komposisi kimia menggunakan spektrometer yaitu pada bagian dinding luar pipa boiler superheater, menunjukkan bahwa baik pipa boiler yang mengalami kegagalan maupun yang utuh masih termasuk kedalam spesifikasi material ASTM A213 T12 yaitu material dengan golongan baja karbon rendah, yang berarti tidak adanya kesalahan dalam pemilihan dan penggunaan material yang sesuai dengan aplikasinya karena memiliki ketahanan terhadap creep yang baik, keuletan yang tinggi,kekerasan yang rendah, mudah dilas, tetapi sifat machineability nya rendah [7].

Dari tabel 2 juga terlihat adanya unsur Krom dan Molybdenum pada hasil pemeriksaan komposisi kimia pada pipa boiler yang pecah, yang jumlahnya berada di luar range komposisi yang diijinkan. Unsur krom merupakan unsur penyusun material utama yang berfungsi untuk meningkatkan ketahanan korosi, ketangguhan serta stabil pada temperatur tinggi. Selain itu juga unsur krom sangat berperan terhadap pembentukkan senyawa karbida yang keras, sehingga akan meningkatkan kekerasan baja tersebut. [8][9]. Jumlah unsur krom yang dibawah range yang seharusnya dimilki oleh material pipa boiler akan mempengaruhi sifat ketahanan korosi serta kekerasan. Hal tersebut

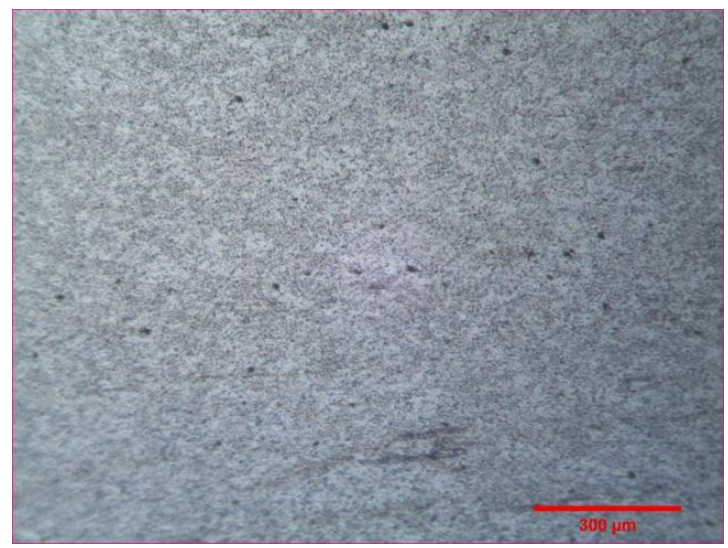

(a) sangat berkaitan dengan nilai kekerasan yang dapat terlihat pada tabel 3 yang menyatakan bahwa nilai kekerasan pada posisi 1 yaitu pada bibir bagian yang mengalami pecah lebih rendah yaitu $123 \mathrm{HV}$ dibandingkan dengan kekerasan pada posisi 2 yang posisinya lebih jauh dari bagian yang pecah yaitu $130 \mathrm{HV}$. Nilai kekerasan yang menurun sebagai akibat material pipa boiler pada posisi 1 mengalami panas berlebih (overheating), dimana pada panas yang tinggi karbida krom yang terbentuk akan mengurai dan berefek pada nilai kekerasan [10][11].

Tabel 2. Hasil Pengujian Komposisi kimia

\begin{tabular}{cccc}
\hline Unsur & Pecah & Utuh & ASTM A213 T12A \\
\hline $\mathbf{C}$ & 0,10 & 0,13 & $0,05-0,15$ \\
$\mathbf{M n}$ & 0,38 & 0,50 & $0,30-0,61$ \\
$\mathbf{P}$ & $<0,0001$ & 0,007 & maks 0,025 \\
$\mathbf{S}$ & 0,060 & 0,025 & maks 0,026 \\
$\mathbf{S i}$ & $<0,0001$ & 0,024 & maks 0,50 \\
$\mathbf{C r}$ & 0,75 & 0,86 & $0,80-1,25$ \\
$\mathbf{M o}$ & 0,52 & 0,43 & $0,44-0,65$ \\
$\mathbf{F e}$ & Balance & Balance & Balance \\
\hline
\end{tabular}

Tabel 3. Nilai kekerasan material pipa boiler superheater

\begin{tabular}{ccccccc}
\hline & \multicolumn{6}{c}{ Kekerasan (HV) } \\
\cline { 2 - 7 } Posisi & $\mathbf{2}$ & $\mathbf{3}$ & $\mathbf{4}$ & $\mathbf{5}$ & $\begin{array}{c}\text { Rata- } \\
\text { rata }\end{array}$ \\
\hline $\mathbf{1}$ & 121,9 & 124,3 & 125,2 & 123,3 & 120,2 & 123,0 \\
$\mathbf{2}$ & 129,8 & 126,9 & 132,0 & 130,0 & 132,6 & 130,3 \\
\hline
\end{tabular}

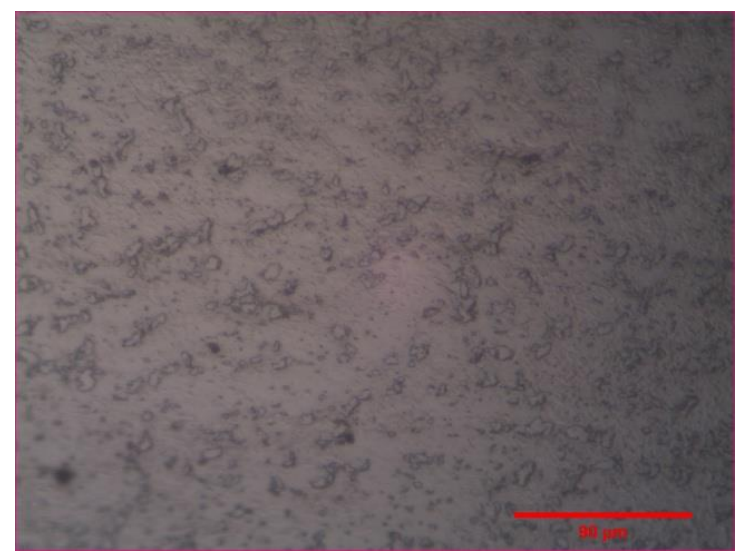

(b)

Gambar 3. (a), (b) Struktur mikro pipa boiler posisi 2 
Gambar 2 dan 3 adalah gambar struktur mikro yang dilakukan pada posisi 1 dan 2 pipa boiler superheater yang mengalami kegagalan. Pada gambar 2(a), pada bagian pipa dekat dengan bgian pecah, terlihat adanya batas butir dari fasa ferit yang menipis dengan ukuran butir semakin besar (terjadi pengkasaran) sebagai akibat telah mengalami sperodisasi apabila dibandingkan pada struktur mikro material ASTM A213 (gambar 4). Pengkasaran ini menunjukkan bahwa area tersebut telah mengalami overheating [12]. Pengkasaran tersebut beserta proses dekarburisasi, dapat ditunjukkan pula pada gambar 2(b) yang dialami oleh pipa, dimana merupakan salah satu penyebab turunnya ketahanan material terhadap creep, yang mengawali terjadinya kerusakan,dan juga terlihat pada permukaan material terjadi korosi sumuran (pitting corrosion) [13].

Gambar 3(a) dan (b) yang merupakan struktur mikro pipa boiler superheater pada posisi 2, terlihat pada gambar tersebut tidak terlihatnya fasa ferit maupun perlit karena terjadi proses dekarburisasi. Menurunnya jumlah karbon pada material pipa boiler dikarenakan pemanasan yang sangat tinggi diatas batas kemampuan materialnya, sehingga unsur karbon akan bereaksi dengan gas-gas oksigen dan hydrogen yang terdapat di lingkungan sekitar pipa boiler superheate. Sedangkan pada gambar 4 menunjukkan struktur mikro pipa yang masih utuh. Struktur mikro yang terlihat adalah fasa ferit dengan garis butiran yang relatif masih jelas. Pada area batas butir dan di dalam area butir terlihat adanya sperodisasi (fasa yang membentuk area butir kecil) dari fasa yang mengandung karbon yang menunjukkan tanda bahwa pipa telah digunakan pada lingkungan temperatur tinggi dalam jangka waktu tertentu.

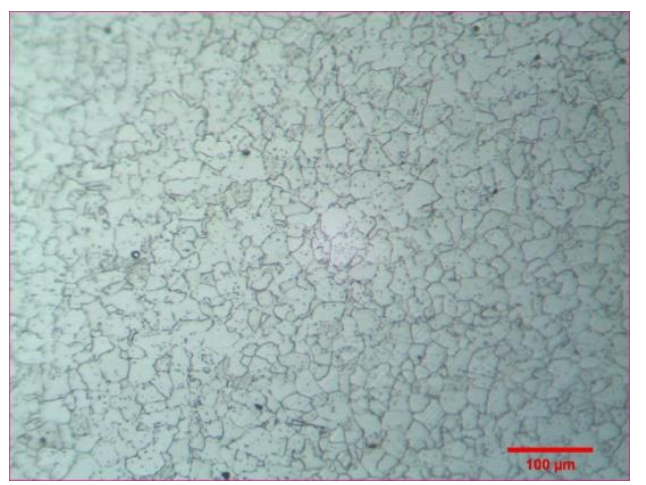

Gambar 4. Gambar struktur mikro pipa boiler utuh (ASTM A213 T12)

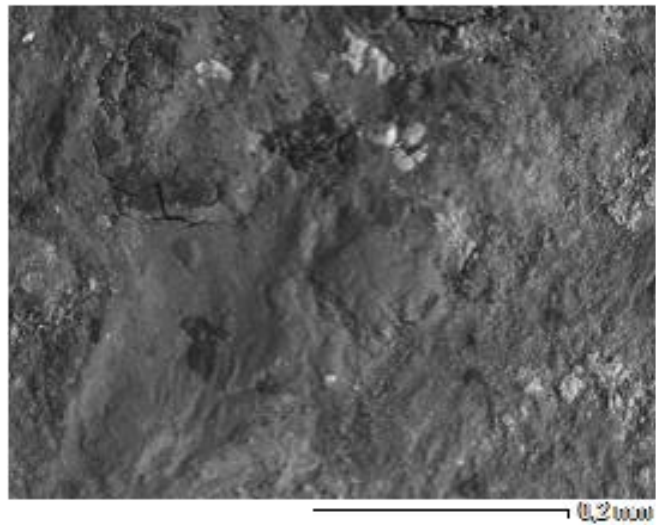

Gambar 5. Hasil SEM pada kerak dipermukaan luar pipa boiler

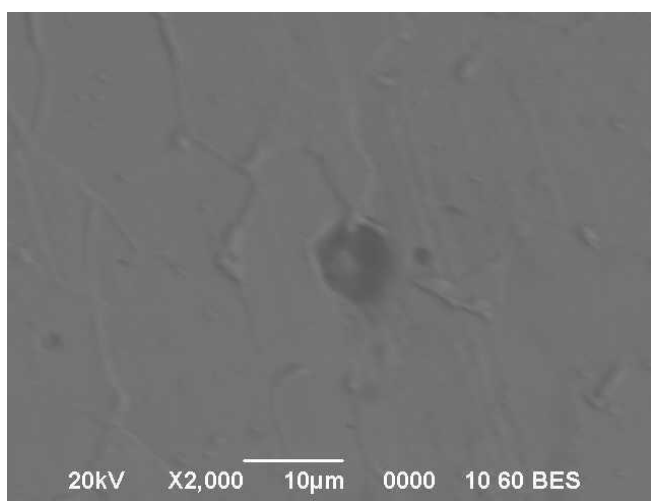

Gambar 6. Hasil SEM pada permukaan luar pipa boiler

Gambar 5 adalah hasil pemeriksaan menggunakan SEM yang dilakukan pada kerak yang berada pada bagian luar permukaan pipa boiler superheater yang mengalami kegagalan. Pemeriksaan produk korosi berupa kerak kemudian dilakukan pemeriksaan

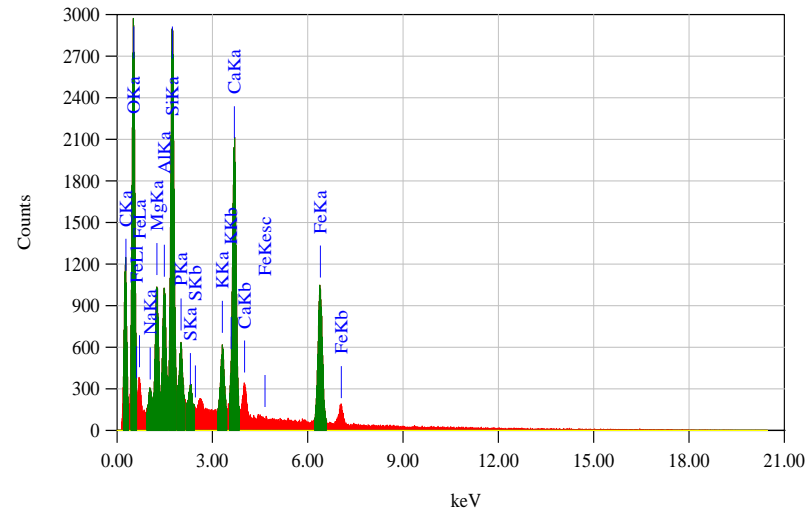

Gambar 7. Hasil EDS pada kerak dipermukaan luar pipa boiler 
menggunaan EDS seperti yang terlihat pada gambar 6, dimana dari hasil EDS tersebut yang dominan adalah $\mathrm{S}, \mathrm{Na}, \mathrm{Ca}, \mathrm{P}, \mathrm{K}, \mathrm{Si}$ yang merupakan unsur korosif yang mempercepat material rusak. Unsurunsur yang keberadaanya diduga berasal dari hasil pembakaran bahan bakar di sistem boiler tersebut kemudian bereaksi dengan udara kemudian membentuk senyawa oksida dan menjadi produk korosi dalam bentuk kerak yang menempel pada permukaan pipa boiler [14].

Pada gambar 7 yang juga hasil pemeriksaan menggunakan SEM dapat dilihat adanya bentuk lubang pada permukaan pipa boiler yang diindikasi sebagai bentuk dari korosi sumuran (pitting corrosion). Korosi sumuran seringkali dianggap jenis korosi sangat serius dibandingkan dengan korosi lainnya karena sangat sulit diprediksi,dimana keberadaannya tidak terlihat secara visual, tetapi memiliki laju korosi yang sangat tinggi karena terlokalisasi sehingga lubang sumuran dengan sangat cepat menembus dinding dan menyebabkan kegagalan tanpa peringatan [15][16]. Lubang sumuran yang terbentuk pada pipa boiler superheater terdapat dibeberapa titik yang terlokalisasi, dan korosi tersebut sudah menembus hingga ke dinding dalam dari pipa boiler, sehingga menjadikan inisiasi kegagalan yang menyebabkan material pipa boiler menjadi rapuh kemudian patah (rusak).

\section{KESIMPULAN}

Metode analisis kegagalan telah dilakukan pada pipa boiler superheater di Pabrik kelapa sawit yang mengalami pecah pada bagian sejajar sumbu axis. Dari hasil beberapa pemeriksaan dan pengujian merusak, dapat diketahui bahwa keberadaan unsur Krom yang dibawah range material ASTM A213 T12 menyebabkan penurunan ketahanan korosi dan nilai kekerasan. Dari hasil pemeriksaan struktur mikro terlihat Batas butir dari fasa ferit pada struktur mikro menipis dengan ukuran butir yang membesar. dari keseluruhan analisis, kegagalan pada pipa boiler superheater adalah adanya creep dan proses dekarburisasi serta korosi sumuran (pitting corrosion).

\section{DAFTAR PUSTAKA}

[1] J. Adrian et al., "Analisa Kerusakan Superheater Tube Boiler Tipe ASTM A213
Grade T11 pada Pembangkit Listrik Tenaga Uap", Jurnal Teknik ITS Vol.5 No 2, pp. 148-152, 2016.

[2] Edwin Lim Chui Seng, Evaluation of High Temperature Boiler Tubes Using Iterative Analytical Approach",Universiti Tunku Abdul Rahman, April 2013

[3] ASTM A213/A213M,"Standard Specification for Seamless Ferritic and Austenitic Alloy-Steel Boiler, Superheater, and Heat Exchanger Tubes, ASTM International

[4] M. Halim, S. Ismail, M. Kamal, and A. Aziz, "Review of Literature on Steam Accumulator Sizing in Palm Oil Mill", European Journal of Scientific Research, November, 2009.

[5] ASTM E92, "Standard Test Method for Vickers Hardness of Metallic Materials", ASTM International

[6] S.R. Lampman, ASM Handbook Volume 9, "Metallography and Microstuctures"

[7] M. Nurbanasari \& Abdurrachim, Investigation of Leakage on Water Wall Tube in a 660 MW Supercritical Boiler", Journal of Failure Analysis and Prevention, Volume 14, No. 5, 2014.

[8] K. Singh, A.Chhabra \& V.Kapoor, "Effect on Hardness \& Micro Structural Behaviour of Tool Steel After Heat Treatment Process", Scholarly Research Journal for Humanity Science \& English Language, 2017

[9] E. Karantzalis, A. Lekatou, and H. Mavros, "Microstructure and properties of high chromium cast irons: effect of heat treatments and alloying additions", International Journal of Cast Metals Research, Vol.22, No. 6. December, 2009.

[10] E.Martides, B.Prawara, E. Junianto, F.R Putri, D.H. Prajitno, "Pengaruh Proses Perlakuan Panas terhadap Nilai Kekerasan Metal Matrix Composite Coating pada Substrat, SS316 untuk Aplikasi Pipa Boiler, Jurnal Metalurgi, Volume 3, pp.101-108, 2018

[11] N.Srisuwan, K.Eidheh, N. Kreatsereekul, T.Yingsamphanchareon, A.Kaewvilai, "The Study of Heat Treatment Effects on Chromium Carbide Precipitation of $35 \mathrm{Cr}$ $45 \mathrm{Ni}-\mathrm{Nb}$ Alloy for, Repairing Furnace Tubes” Journal Metals, MDPI,no. 1, 2016.

[12] M. Asnavandi, M. Kahram, M. Rezaei, and D. Rezakhani, "Fire-Side Corrosion: A Case Study of Failed Tubes of a Fossil Fuel Boiler 
Fire-Side Corrosion : A Case Study of Failed Tubes of a Fossil Fuel Boiler", International Journal of Corrosion,. January, 2017.

[13] W. Liu and W. Liu, "The dynamic creep rupture of a secondary superheater tube in a 43 MW coal-fired boiler by the decarburization and multilayer oxide scale buildup on both sides," Eng. Fail. Anal., 2015.

[14] A.A.Khadom, A.A.Fadhil, A.M.A Karim, H.Liu. Journal, "Effect Of Hot Corrosion On Boilers Pipes In North Baghdad Electric Power Plant Station", Diyala Journal of Engineering Sciences, pp. 776-784, 2015.

[15] D. W. Hoeppner and C. A. Arriscorreta, "Exfoliation Corrosion and Pitting Corrosion and Their Role in Fatigue Predictive Modeling: State-of-the-Art Review", International Journal of Aerospace Engineering, 2012.

[16] E. Sarver and M. Edwards, "Inhibition of Copper Pitting Corrosion in Aggressive Potable Waters", International Journal of Corrosion, 2012. 